\title{
The Effect of Message-Framing on Breastfeeding Self-Efficacy Among Nulliparous Women in Shushtar, Iran
}

\author{
Fatemeh Merdasi ${ }^{1}$, Marzieh Araban ${ }^{2}$, Malehi Amal Saki ${ }^{3}$
}

\begin{abstract}
${ }^{1}$ Health Education Student, Public Health School, Ahvaz Jundishapur University of Medical Sciences, Ahvaz, Iran ${ }^{2}$ Ph.D. in Health Education, Assistant Professor, Social Determinants of Health Research Center, Health Education and Health Promotion Department, Ahvaz Jundishapur University of Medical Sciences, Ahvaz, Iran

${ }^{3}$ Ph.D. of Biostatistics, Assistant Professor, Department of Biostatistics and Epidemiology, Faculty of Health, Ahvaz Jundishapur University of Medical Sciences, Ahvaz, Iran
\end{abstract}

\section{Type of article: Original}

\begin{abstract}
Introduction: Exclusive breastfeeding for 6 months and continuing it for 2 years, along with complementary feeding, are the primary objectives of public health plans and nutrition around the world. Self-efficacy is a theoretical framework that could be a strong predictive for breastfeeding. This study aimed to determine the effect of message-framing on self-efficacy of breastfeeding in nulliparous women in Shushtar.

Methods: This quasi-experimental study was conducted in 2015 on 210 nulliparous women in Shushtar (Iran). The participants were randomly allocated into intervention and control groups. The study tool was the short form of breastfeeding self-efficacy scale that was completed on arrival of the study (days 3-5), at the end of week four and at the end of week eight. Data were analyzed by SPSS 19, using Chi-square, ANOVA, and repeated measurements.

Results: Mean age of participants was 24.52 years old with standard deviation of 95.4. Mean score of breastfeeding self-efficacy in gain-framed group at days 3-5, week four and week eight was 47.94, 57.43 and 52.8 respectively; in loss-framed group it was $47.76,56.11$ and 52.64 respectively; and in control group it was 45.16, 48.68 and 45.31 respectively. No significant difference was observed between the score of average self-efficacy of days 3-5 and week eight in control group $(\mathrm{p}=0.93)$. However, in gain-framed group $(\mathrm{p}=0.001)$ and loss-framed group ( $\mathrm{p}=0.004)$, a significant difference was observed.

Conclusion: Results of this study showed that message-framing promotes breastfeeding self-efficacy in nulliparous women and in this regard, there is no difference between gain-framed and loss-framed messages.

Keywords: Breastfeeding Self-Efficacy; Nulliparous Women; Message-Framing
\end{abstract}

\section{Introduction}

Exclusive breastfeeding for 6 months and continuing it for 2 years along with complementary feeding, are the primary goals of public health plans and nutrition worldwide. Short-term benefits of breastfeeding include reduction of neonatal morbidity and mortality because of infectious diseases. While, in the long run, benefits like academic success, reduction of hypertension, reduced incidence of high cholesterol and obesity in older ages can be observed (1). Breastfeeding results in neonates' growth and development, and reduces the possibility of respiratory and gastrointestinal infections, reduced sudden infant death syndrome, reduced prevalence of type I and type II diabetes and reduced childhood cancers. It also reduces the rate of middle ear infections, skin infections and the risk of obesity and asthma, and mortality as a result of these diseases, is reduced while breastfeeding (2). Considering the important role of breastfeeding in preventing malnutrition and neonatal mortality and creating emotional connection between mother and infant, one of the objectives of peoples' health plan is to increase breastfeeding to $75 \%$ after

\section{Corresponding author:}

Assistant Professor Dr. Marzieh Araban, Social Determinants of Health Research Center, Health Education and Health Promotion Department, Ahvaz Jundishapur University of Medical Sciences, Ahvaz, Iran.

Tel: +98.6133738269, Fax:+98.6133738282, Email: arabanm@ajums.ac.ir, and araban62@gmail.com

Received: July 14, 2016, Accepted: August 08, 2016, Published: January 2017

iThenticate screening: August 02, 2016, English editing: December 12, 2016, Quality control: January 05, 2017

(C) 2017 The Authors. This is an open access article under the terms of the Creative Commons Attribution-NonCommercialNoDerivs License, which permits use and distribution in any medium, provided the original work is properly cited, the use is non-commercial and no modifications or adaptations are made. 
delivery and to $50 \%$ at 6 months (3). If breastfeeding is promoted according to peoples' health plan of the WHO, it will bring about 3.6 billion dollars of economic efficiency (4). However, according to the WHO, in 2011, about half of the children around the world enjoyed exclusive breastfeeding (5). In the United States, relatively $70 \%$ of women start breastfeeding for their infants; however, only $40 \%$ of them continue breastfeeding for 6 months and only $25 \%$ of children enjoy breastfeeding up to 1 year of age (6). In Australia, $80 \%$ of women start breastfeeding after delivery. However, only $60 \%$ of them continue it for 3 months and $18 \%$ for 6 months (7). In Iran, exclusive breastfeeding is very low and the index of exclusive breastfeeding in 2005 is reported to be only $23.7 \%$ for the entire country. Khuzestan Province, with an index of $19.5 \%$ has shown a significant decrease in exclusive breastfeeding relative to other provinces (8). Various factors affect breastfeeding, including social factors and demographic factors as well as behavioral-psychological factors (9). One of the behavioral-psychological factors that can be regarded as a theoretical framework for interventions is self-efficacy, in such a way that breastfeeding self-efficacy can be regarded as the strongest predictor of breastfeeding (10). Self-efficacy is peoples' belief in their abilities to perform a special behavior (11). Therefore, breastfeeding self-efficacy means a woman's belief in her ability to breastfeed (12). Considering that breastfeeding self-efficacy in mothers is affected by their previous experiences, nulliparous women will encounter problems in exclusive breastfeeding, due to the lack of previous experience. With regard to reduced breastfeeding in recent years in Iran, it appears that it is of special importance to develop appropriate strategies to increase breastfeeding self-efficacy, especially in nulliparous women (13). When people are in a condition of benefit and loss, they somehow refrain from risks; however, when they encounter a range of benefits and losses, they relatively seek risks. According to the theory of message-framing, framing or presenting completely similar information on decision-making under uncertainty, conditions can be performed via these two ways: potential benefits or potential losses. Information framing can affect data-coding related to health by people. People respond differently to information framed in the form of benefits and losses (14). Salovey and Rothman presented two theories on framing. First, loss-framed messages act more effectively for people who are engaged with behavior related to screening or early diagnosis. Secondly, gain-framed messages act more effectively for people who are engaged with behavior with definite outcomes or preventive behavior (15). In 2012, the study by Pakpour Haji Agha et al. in Qazvin, showed that teenagers encountering loss-framed messages show better attitudes towards using toothbrush and floss (16). The study by van't Riet et al. also showed that self-efficacy level plays an important role in the effects of gain-framed and loss-framed messages (17). Results of the study by Goodall and Appiah showed that teenagers have a good attitude towards loss-framed messages and perceive them as being more effective, compared to gain-framed ones (18). The aim of designing this study was to see whether gains and losses resulted from breastfeeding, can improve breastfeeding self-efficacy in mothers, or benefits and losses resulted from feeding with other milks. Therefore, in this study, the effect of message-framing on breastfeeding self-efficacy of nulliparous women is investigated in Shushtar, Iran.

\section{Material and Methods}

\subsection{Research design}

This quasi-experimental study was conducted in 2015 on 210 eligible nulliparous women, referring to Thyroid Screening Center of Shushtar, who were willing to enter this study.

\subsection{Sampling}

\subsubsection{Sample size:}

Sample size was 210 subjects, based on the results of study by Mir Mohammad Ali'i et al. (19), using NCCS application with the study power of $80 \%$, considering the possibility of sample loss.

2.2.2. Sampling method:

Random sampling was conducted via 3 ballots under the names of gain-framed, loss-framed and control messages in a bag. For each eligible mother entered in to the study, balloting was conducted and each mother was attributed to one of the three groups.

\subsection{Selection criteria}

\subsubsection{Inclusion criteria:}

Inclusion criteria were: being nulliparous, delivering healthy and term infants with no contra indication for breastfeeding, having no psychological problem in the mother, the intention for breastfeeding, the consent to participate in the study, having the opportunity for texting mothers, fluency in Persian language, absence of abnormality in breast and being singleton. 


\subsubsection{Exclusion criteria:}

Exclusion criteria included: lack of opportunity for texting, mother's unwillingness to continue cooperation, separation of mother and infant, medications that are contraindicated for breastfeeding, and the infant suffering from problems that result in breastfeeding disorder (including neuro-motor disorders, cardiorespiratory and metabolic problems as well as other abnormalities or medical problems).

\subsection{Instrument and procedures}

The main factor that confounds breastfeeding self-efficacy, is maternal parity. Therefore, this research was performed on nulliparous women. More importantly, breastfeeding self-efficacy is measured via a scale which is not affected by any special feature (12). In total, 70 mothers were attributed to gain-framed group and 70 mothers to loss-framed group. This study was a questionnaire, the first part of which, includes demographic details as well as the history of pregnancy, including mother's age, ethnicity, type of pregnancy, type of delivery, infant's gender, pregnancy age, mother's occupation, monthly family income, mother's education and husband's education. The second part of questionnaire included the amount of breastfeeding self-efficacy obtained from the short form of Dennis Breastfeeding Self-Efficacy Scale (BSES-SF), the validity and reliability of which, has been investigated earlier and includes 13 questions designed as 5-point Likert scale. Self-efficacy score was between 13 and 65 . In the first stage, this questionnaire was filled by mothers before intervention, at days $3-5$, in person, and all mothers were trained in person, in terms of correct breastfeeding, methods of milking and storing it, advantages of breastfeeding and disadvantages of artificial or cow milk, and disadvantages of early complementary feeding and verbal encouragement for breastfeeding. Then, for four weeks, one message per day and from weeks four to eight, a positive message was sent to gain-framed group (e.g. breastfeeding increases children's IQ) and a negative message was sent to loss-framed group (e.g. symptoms such as diarrhea and intestinal bleeding is observed more in infants fed with milk other than their mothers') every other day, and mothers were asked to text an empty message after receiving these texts for researcher's confidence. The control group received no texts. Validity and reliability of messages was confirmed using validity checklist of messages. After weeks four and eight, this questionnaire was refilled by mothers via phone call.

\subsection{Statistical analysis}

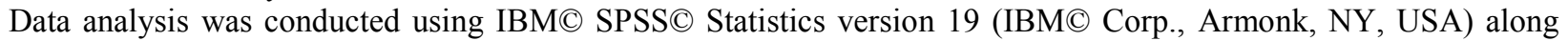
with Chi square test, ANOVA, and repeated measurements. In all tests, confidence interval of $95 \%$, and significance level of $5 \%$ were considered.

\subsection{Ethics approval}

This study was approved by the Ethics Committee of Ahvaz University of Medical Sciences with letter number SDH-9412.

\section{Results}

This study was conducted on 210 nulliparous women in Shushtar, who were selected randomly and included in the study. Three subjects from control group and 6 subjects from intervention group did not fill the questionnaire, due to the change of location and not answering the phone in week eight. Overall, samples included 67 women in gainframed group, 67 women in loss-framed group and 67 women in control group. All three groups were homogenous in terms of demographic details, and no significant difference was observed. Participants were between 16 and 40 years of age with mean age of 24.52 and standard deviation of 4.95 . Of participants who had academic degrees, there were $27.6 \%$, and the highest frequency was related to diploma for $45.8 \%$. Of participants who were housewives, there were $89.2 \%$, and most infants were boys $(53.2 \%$ ) (Table 1,2). In intervention groups, a significant difference was observed between average breastfeeding self-efficacy score, before and after intervention. However, in control group, no significant difference was observed between breastfeeding self-efficacy score, before and after intervention. In terms of comparing average breastfeeding self-efficacy score before and after intervention, no significant difference was observed between gain-framed and loss-framed groups. However, in terms of comparing average breastfeeding self-efficacy score before and after intervention, a significant difference was observed between control and intervention groups (Table 3). After analyzing repeated measurement that expressed the difference between groups, LSD post hoc test was employed, the results of which, indicate that average breastfeeding self-efficacy score in weeks four and eight, relative to days three to five, showed a significant difference both in gain-framed and loss-framed group. On the other hand, a significant difference was also observed between weeks four and eight relative to each other. In control group, average breastfeeding self-efficacy score 
showed a significant difference between 3-5 days of age and week four. However, no significant difference was observed between average self-efficacy score of days 3-5 and week 8 , in control group.

Table 1. Maternal age and gestational age of the Participants

\begin{tabular}{|l|l|l|l|l|}
\hline Variable & Gain & Loss & Control & p-value (ANOVA) \\
\hline Maternal age (year) & $24.33 \pm 4.5$ & $23.61 \pm 4.25$ & $25.63 \pm 5.83$ & 0.058 \\
\hline Gestational age (week) & $39.42 \pm 1.26$ & $39.45 \pm 1.27$ & $39.69 \pm 1.28$ & 0.41 \\
\hline
\end{tabular}

Table 2. Demographics of the Participants

\begin{tabular}{|c|c|c|c|c|c|}
\hline \multicolumn{2}{|l|}{ Variables } & Gain; $\mathrm{n}(\%)$ & Loss; $\mathrm{n}(\%)$ & Control; n (\%) & $\mathrm{p}$-value \\
\hline \multirow[t]{3}{*}{ Ethnicity } & Lur & $31(46.3)$ & $42(62.7)$ & $32(47.8)$ & \multirow[t]{3}{*}{0.22} \\
\hline & Fars & $16(23.9)$ & $15(22.4)$ & $17(25.4)$ & \\
\hline & Arab & $20(29.9)$ & $10(14.9)$ & $18(26.9)$ & \\
\hline \multirow[t]{4}{*}{ Type of Pregnancy } & Planned by women & $1(1.5)$ & $2(3)$ & $1(1.5)$ & \multirow[t]{4}{*}{0.85} \\
\hline & Planned by husband & $1(1.5)$ & $2(3)$ & $4(4)$ & \\
\hline & Planned by both & $63(94)$ & $60(86.9)$ & $60(86.9)$ & \\
\hline & Unplanned & $2(3)$ & $3(4.5)$ & $2(3)$ & \\
\hline \multirow[t]{2}{*}{ Baby gender } & Female & $33(49.3)$ & $28(41.8)$ & $32(47.8)$ & \multirow[t]{2}{*}{0.66} \\
\hline & Male & $34(50.7)$ & $28(41.8)$ & $35(52.2)$ & \\
\hline \multirow[t]{2}{*}{ Type of delivery } & Normal & $41(49.3)$ & $37(55.2)$ & $39(58.2)$ & \multirow[t]{2}{*}{0.78} \\
\hline & Caesarean & $26(38.8)$ & $30(44.8)$ & $28(41.8)$ & \\
\hline \multirow[t]{3}{*}{ Family income } & Low & $27(40.3)$ & $31(46.3)$ & $18(26.9)$ & \multirow[t]{3}{*}{0.1} \\
\hline & Fair & $33(49.3)$ & $26(38.8)$ & $34(50.7)$ & \\
\hline & Good & $7(10.7)$ & $10(14.9)$ & $15(22.4)$ & \\
\hline \multirow[t]{2}{*}{ Woman occupation } & Housewife & $60(89.6)$ & $59(88.1)$ & $62(92.5)$ & \multirow[t]{2}{*}{0.68} \\
\hline & Practitioner & $7(10.7)$ & $8(11.9)$ & $5(7.5)$ & \\
\hline \multirow[t]{5}{*}{ Husband occupation } & Work less & $3(4.5)$ & $2(3)$ & $1(1.5)$ & \multirow[t]{5}{*}{0.87} \\
\hline & Labour & $26(38.8)$ & $31(46.3)$ & $25(37.3)$ & \\
\hline & Student & $3(4.5)$ & $4(6)$ & $3(4.5)$ & \\
\hline & Self-employment & $24(35.8)$ & $22(32.8)$ & $30(44.8)$ & \\
\hline & Employee & $11(16.4)$ & $8(11.9)$ & $8(11.9)$ & \\
\hline \multirow[t]{4}{*}{ Women education } & Primary & $9(13.4)$ & $7(10.4)$ & $8(11.9)$ & \multirow[t]{4}{*}{0.95} \\
\hline & Secondary school 1 & $10(14.9)$ & $7(10.4)$ & $11(16.4)$ & \\
\hline & Secondary school 2 & $31(46.3)$ & $32(47.8)$ & $30(44.8)$ & \\
\hline & Collegiate & $11(16.4)$ & $21(31.3)$ & $18(9.26)$ & \\
\hline \multirow[t]{4}{*}{ Husband education } & Primary & $8(11.9)$ & $3(4.5)$ & $7(10.4)$ & \multirow[t]{4}{*}{0.31} \\
\hline & Secondary school 1 & $14(20.9)$ & $15(22.4)$ & $20(29.9)$ & \\
\hline & Secondary school 2 & $30(44.8)$ & $35(52.2)$ & $22(32.5)$ & \\
\hline & Collegiate & $15(22.4)$ & $14(20.9)$ & $18(26.9)$ & \\
\hline
\end{tabular}

Table 3. Breastfeeding self-efficacy in study groups over time

\begin{tabular}{|l|l|l|l|l|}
\hline Time & $\begin{array}{l}\text { Gain } \\
\text { Mean } \pm \text { SD }\end{array}$ & $\begin{array}{l}\text { Loss } \\
\text { Mean } \pm \text { SD }\end{array}$ & $\begin{array}{l}\text { Control } \\
\text { Mean } \pm \text { SD }\end{array}$ & $\begin{array}{l}\text { Between groups } \\
\text { p-value* }\end{array}$ \\
\hline 3-5 days & $47.94 \pm 10.6$ & $47.76 \pm 10.69$ & $45.16 \pm 10.33$ & 0.001 \\
\hline 4 weeks & $57.43 \pm 7.98$ & $56.11 \pm 8.57$ & $48.68 \pm 9.75$ & \\
\hline 8weeks & $52.8 \pm 7.93$ & $52.64 \pm 8.73$ & $45.31 \pm 10.98$ & \\
\cline { 1 - 3 } $\begin{array}{l}\text { Within groups } \\
\text { p-value* }\end{array}$ & 0.001 & 0.001 & 0.07 & \\
\cline { 1 - 3 } & & & & \\
\hline
\end{tabular}

*Repeated measurement

\section{Discussion}

This study was conducted with the aim of investigating the effect of message-framing on self-efficacy and breastfeeding behavior in nulliparous women in Shushtar. Results of this study showed that message-framing increased self-efficacy in weeks four and eight after delivery in intervention groups, and no significant difference 
was observed between gain-framed and loss-framed messages. Breastfeeding self-efficacy in control group in week four after delivery, was significantly different relative to days three to five and it appears that two factors affect this issue. First, personal training in days three to five to all mothers and secondly, the factor of direct experience which is the main concept in self-efficacy. Therefore, breastfeeding self-efficacy in nulliparous women, increased after week four of breastfeeding. However, in week eight after delivery, breastfeeding self-efficacy showed no significant difference relative to days three to five. As Chen et al. reported, texting can increase care up to $87 \%$ (21). In this regard, Peter et al. showed that foot care in diabetic patients increased significantly after 12 months' phone followup (22). In a study, Sacco et al. found that regular phone intervention for 6 months, results in continued compliance with the exercise program in diabetic type II patients (23). In a study conducted by Oh and Kim, to investigate the effect of phone calls by nurses for diabetes control, after 12 weeks of phone intervention, adherence to diet increased significantly (24). In terms of the effect of message-framing on diet behavior, results showed that there is no significant difference between average of observing diet in gain-framed and loss-framed groups. In this regard, findings of meta-analysis study by O'Keefe et al., conducted with the aim of investigating the effect of gain-framed and loss-framed messages on behavior related to obesity, showed that there is no significant difference between gain-framed and loss-framed messages in promoting healthy diet (25) and they comply with the findings of present study. In addition, in a study conducted on 143 women convicted in the court, to investigate message-framing on conducting screening test for herpes simplex 1 , results showed that there is no significant difference between gainframed and loss-framed messages in encouraging women to conduct tests (26). Results of the study by Daniel et al. showed that there is no significant difference between gain-framed and loss-framed messages in promoting skin cancer preventive behavior (27), which complies with results of current study. Results of the study by Bong et al. with the aim of comparing the effect of loss-framed messages in diabetes mellitus training on 99 patients with diabetes type II, showed the effect of loss-framed messages on increasing foot care attitude, intention and behavior that contradicts with the results of current study (28). The study conducted by Pakpour Haji Agha et al., with the aim of comparing the effect of gain-framed and loss-framed messages on increasing attitude and behavioral intention, related to teeth and mouth health of middle school students of Qazvin, showed the effect of loss-framed messages on motivating students to perform behavior related to teeth and mouth health (16). Results of the study conducted by Janet et al. showed that foot care behavior score increased significantly, after 6 months in the group that received gain-framed messages, relative to another group (29). This lack of compliance between results of various studies can be the result of research method and personal characteristics of people, some part of which, is due to their previous experiences and mentality as well as research variables.

\section{Limitations of the Study}

Lack of possibility to text all participants of intervention groups at the same time, because of the schedule planned in this study was one of the hardships of intervention, in addition to the lack of sufficient cooperation of mothers to text an empty message that resulted in researcher's calling to confirm text delivery.

\section{Conclusions}

Results of this study showed that message-framing increased self-efficacy in weeks four and eight after delivery in intervention groups, and no significant difference was observed between gain-framed and loss-framed messages. The practical importance of the findings of this study lies in the fact that message-framing can promote breastfeeding self-efficacy. Therefore, it is suggested to employ gain-framed and loss-framed messages to increase self-efficacy in nulliparous women. Conducting a complementary research on the effect of message-framing on breastfeeding self-efficacy of nulliparous women in other societies with a different methodology, can be an appropriate path for future studies on this issue.

\section{Acknowledgments:}

This study was derived from a master's thesis and the approved project of research center of social factors affecting health, SDH 9412 in Ahvaz Jundishapur University of Medical Sciences. All women who participated in this study are appreciated.

\section{Conflict of Interest:}

There is no conflict of interest to be declared.

Authors' contributions:

All authors contributed to this project and article equally. All authors read and approved the final manuscript. 


\section{References:}

1) Horta BL, Bahl R, Martines JC, Victora CG. Evidence on the long-term effects of breastfeeding. WHO Geneva. 2007.

2) Leon-Cava N, Lutter C, Ross J, Martin L. Quntifying the benefits of breastfeeding: a summary of the evidence. PAHO Washington DC. 2002.

3) Wong DL, Hockenberry-Eaton M, Wilson D, Winkelstein LM, Ahmann E, Divito-Thomas PA. Whaley \& Wong's Nursing Care of Infants and Children. St. Louis: Mosby Co. 1999.

4) Bartick M, Reinhold A. The burden of suboptimal breastfeeding in the United States: a pediatric cost analysis. Pediatrics. 2010; 125(5): 1048-56. doi: 10.1542/peds.2009-1616. PMID: 20368314.

5) Wu DS, Hu J, McCoy TP, Efird JT. The effects of a breastfeeding self-efficacy intervention on short-term breastfeeding outcomes among primiparous mothers in Wuhan, China. J Adv Nurs. 2014; 70(8): 1867-79. doi: 10.1111/jan.12349. PMID: 24400967.

6) Forster DA, McLachlan HL. Breastfeeding Initiation and Birth Setting Practices: A Review of the Literature. J Midwifery Womens Health. 2007; 52(3): 273-80. doi: 10.1016/j.jmwh.2006.12.016. PMID: 17467594.

7) Donath S, Amir L. Rates of breastfeeding in Australia by state and socio-economic status: Evidence from the 1995 National Health Survey. J Paediatr Child Health. 2000; 36(2): 164-8. doi: 10.1046/j.14401754.2000.00486.x. PMID: 10760016.

8) Varei SH, Mehrdad N, Bahrani N. The relation between breastfeeding self efficacy and position of breastfeeding in mothers. Journal of Nursing\& midwifery faculty of Tehran university of medical sciences. 2009; 15(3): 31-38.

9) Victora CG, Smith PG, Vaughan JP, Nobre LC, Lombardi C, Teixeira AM, et al. Evidence for protection by breast-feeding against infant deaths from infectious diseases in Brazil. Lancet. 1987; 2(8554): 319-22. doi: 10.1016/S0140-6736(87)90902-0. PMID: 2886775.

10) Victora CG, Barros FC, Vaughan JP, Teixeira AM. Birthweight and infant mortality: a longitudinal study of 5914 Brazilian children. Int J Epidemiol. 1987; 16(2): 239-45. doi: 10.1093/ije/16.2.239. PMID: 3610450

11) Bandura A. self-efficacy: Toward a unifying theory of behavioral change. Psychol Rev. 1977; 84(2): 191 215. doi: 10.1037/0033-295X.84.2.191. PMID: 847061.

12) Dennis CL. Theoretical underpinning of breastfeeding confidence: A self-efficacy framework. J Hum Lact. 1999; 15(3): 195-201. doi: 10.1177/089033449901500303. PMID: 10578797.

13) Azhari S, Baghany R, Akhlaghi F, EbrahimZadeh S, Salehi J. Comparison of two methods of training on breastfeeding self efficacy in primiparous mothers. Sabzevar University of Medical Sciences Journal. 2009; 17(4): 244-51.

14) Banks SM, Salovey P, Greener S, Rothman AJ, Moyer A, Beauvais J, et al. The effects of message framing on mammography utilization. Health psychology. 1995; 14(2): 178-84. doi: 10.1037/0278-6133.14.2.178. PMID: 7789354.

15) Rothman AJ, Salovey P. Shaping perceptions to motivate healthy behavior: the role of message framing. Psychol Bull. 1997; 121(1): 3-19. doi: 10.1037/0033-2909.121.1.3. PMID: 9000890.

16) Pakpour Haji Agha A, Nourozi S, Yekaninejad MS, Mansouri A, Chaibakhsh S. Effect of message framing on improving oral health behaviors in students in Qazvin, Iran. Journal of Isfahan Dental School. 2013; 8(6): 512-21.

17) Van 't Riet J, Ruiter RA, Werrij MQ, De Vries H. Self-efficacy moderates message-framing effects: The case of skin-cancer detection. Psychol Health. 2010; 25(3): 339-49. doi: 10.1080/08870440802530798. PMID: 20204928.

18) Goodall C, Appiah O. Adolescents' perceptions of Canadian cigarette package warning labels: investigating the effects of message framing. Health Commun. 2008; 23(2): 117-27. doi: 10.1080/10410230801967825. PMID: 18443999.

19) Mirmohammad Ali M, Bahiraii A, Rahimi A, Hashemzadeh M, Sohrabi N, Sohrabi Z. Effect of educational package on breastfeeding self-efficacy in postpartum period. Payesh. 2014; 13(2): 221-8.

20) Araban M, Falahiyan Mehrjardi F, Shahry P, Montazeri A. The Persian version of Breastfeeding SelfEfficacy Scale-Short Form (BSES-SF): translation and psychometric assessment. Payesh. 2016; 15(1): 8793.

21) Chen ZW, Fang LZ, Chen LY, Dai HL. Comparison of an SMS text messaging and phone reminder to improve attendance at a health promotion center: a randomized controlled trial. Journal of Zhejiang University Science B. 2008; 9(1): 34-8. 
22) Piette JD, Weinberger M, Kraemer FB, Mcphee SJ. impact of Automated Calls with Nurse Follow-UP on Diabetes Treatment Outcomes in a Department Health Care System : a randomized controlled trial. Diabetes Care. 2001; 24(2): 202-8. doi: 10.2337/diacare.24.2.202. PMID: 11213866.

23) Sacco WP, Malone JI, Morrison AD, Friedman A, Wells K. Effect of a brief, regular telephone intervention by paraprofessionals for type 2 diabetes. J Behav Med. 2009; 32(4): 349-59. doi: 10.1007/s10865-0099209-4. PMID: 19365719.

24) Kim HS, Oh JA. Adherence to diabetes control recommendations: impact of nurse telephone calls. J Adv Nurs. 2003; 44(3): 256-61. doi: 10.1046/j.1365-2648.2003.02800.x. PMID: 14641395.

25) O'Keefe DJ, Jensen JD. The relative effectiveness of gain-framed and loss-framed persuasive appeals concerning obesity-related behaviors: Meta-analytic evidence and implications. Leveraging consumer psychology for effective health communications: The obesity challenge. 2011; 171-85.

26) Roth AM, Van Der Pol B, Fortenberry JD, Dodge B, Reece M, Certo D, et al. The Impact of Brief Messages on HSV-2 Screening Uptake Among Female Defendants in a Court Setting: A Randomized Controlled Trial Utilizing Prospect Theory. J Health Commun. 2015; 20(2): 230-6. doi: 10.1080/10810730.2014.920062. PMID: 25494832, PMCID: PMC4356496.

27) O'Keefe DJ, Wu D. Gain-framed messages do not motivate sun protection: A meta-analytic review of randomized trials comparing gain-framed and loss-framed appeals for promoting skin cancer prevention. Int J Environ Res Public Health. 2012; 9(6): 2121-33. doi: 10.3390/ijerph9062121. PMID: 22829794, PMCID: PMC3397368.

28) Lee BJ, Gu MO. Comparison of the effects between positive message and negative message in diabetes mellitus education. Korean Diabetes Journal. 2009; 33(4): 344-52. doi: 10.4093/kdj.2009.33.4.344.

29) Grady JL, Entin EB, Entin EE, Brunyé TT. Using message framing to achieve long-term behavioral changes in persons with diabetes. Appl Nurs Res. 2011; 24(1): 22-8. doi: 10.1016/j.apnr.2009.03.007. PMID: 20974059. 